\title{
Short (5.0 x 5.0 mm) Dental Implant Placement: A Case Report with 3 Year Follow Up
}

\author{
Sumit Munjal ${ }^{1 *}$ and Seema Munjal ${ }^{2}$ \\ ${ }^{1}$ Professor, Department of Peridontics, Institute of Dental Studies and Technologies, UP, India \\ ${ }^{2}$ Reader, Department of Prosthodontics, Crown \& Bridge, Faces $n$ Braces Dental Research Centre, New Delhi, India
}

*Corresponding author: Sumit Munjal, Professor Department of Periodontics, Institute of Dental studies and Technologies, UP, India

Received: 佣 October 23, 2019

Published: 紫 October 29, 2019

\begin{abstract}
The goal of implant rehabilitation is to achieve initial stability and sustain functional loads. Longer than $10 \mathrm{~mm}$ implants provide an increased area to facilitate osseointegration and so the rationale was unquestioned for many years. However, the resorbed posterior maxilla poses a challenge. The feasibility of $7 \mathrm{~mm}$ size was analyzed but failures were seen by the Branemark and other systems that followed. With the improvisation in surface textures in recent years, short and wide fixtures have proven predictable. A successful attempt was shown in the present study with the $5 \times 5$ fixture and assessed three-year post loading clinicoradiographically.
\end{abstract}

Keywords: Short implants, Posterior, Maxilla, Clinic-radiographical

\section{Introduction}

The surface area of implants placed in posterior maxilla must be optimized for functional loads. Available data suggests that longer implants score better than shorter ones [1] because area increases proportional to the length. The volume and the density of bone in the edentulous site are primary determinants for success, [2,3] but both are compromised following resorption and simultaneous pneumatization of sinus. The Branemark system was evaluated for maximum failures placed in this site [4]. Unlike the subperiosteal implants used in bone deficiency, the endosseous technique demands an aggressive sinus lift with augmentation. A recent analysis compared the size $6 \mathrm{~mm}$ Vs 11-15 $\mathrm{mm}$ and reported similar outcomes [5]. In the present study a $5 \times 5 \mathrm{~mm}$ fixture was assessed clinic-radiographically till first annual checkup.

\section{Case Report}

A 51-year female, non- smoker and non- Bruxer, reported to the Faces n Braces Dental institute, New Delhi with a desire to replace an extracted 17 six months ago. A thorough medical \& dental history, and investigations were done, to rule out systemic, as well as local contraindications. The $\mathrm{X}$ ray and later the CT scan revealed an adequate bucco-lingual cortical bone width ie.7.5 $\mathrm{mm}$ but only $7 \mathrm{~mm}$ distance from the crest to the sinus floor at the proposed $2^{\text {nd }}$ molar site. On the day of surgery, a written consent-to-treat agreement was obtained with a description of risk and benefits. She was made to rinse with $10 \mathrm{ml}$. of chlorhexidine gluconate followed by extraoral scrubbing with $5 \%$ Povidine iodine.

Both midcrestal and crevicular incisions were given under the nerve block in order to elevate the mucoperiosteal flap (Figure 1). The osteotomy was started with pilot drill under $900 \mathrm{rpm}$ speed with an intermittent pressure of 1 second on the bone and 1 to 2 seconds off the bone. Maintaining the depth stop at $5 \mathrm{~mm}$ under copious saline irrigation but changing the speed to $400 \mathrm{rpm}$, a sequential widening was done using $2.8,3.2$ and lastly $3.8 \mathrm{~mm}$ twist drills (Figure 2). As planned, a short( $5 \times 5$ ) external hex Tixos implant from Leader, Italy was removed from a sterile vial (Figure 3). The installation was engaged on a 20:1 gear reduction handpiece, through a premounted abutment and seated into the osteotomy under $25 \mathrm{rpm}$. A particulate bone graft was ensured circumferentially along the body of fixture after confirming the primary stability and that no implant thread was visible outside the crest site (Figure 4). The same mount was removed with the help of a hex driver and replaced with the cover screw. 4.0 Ethicon resorbable sutures were used for primary closure and a provisional crown was provided in infraocclusion. The drugs diclofenac sodium $100 \mathrm{mg}$ bid and amoxicillin $500 \mathrm{mg}$ bid were prescribed for 5 days. 


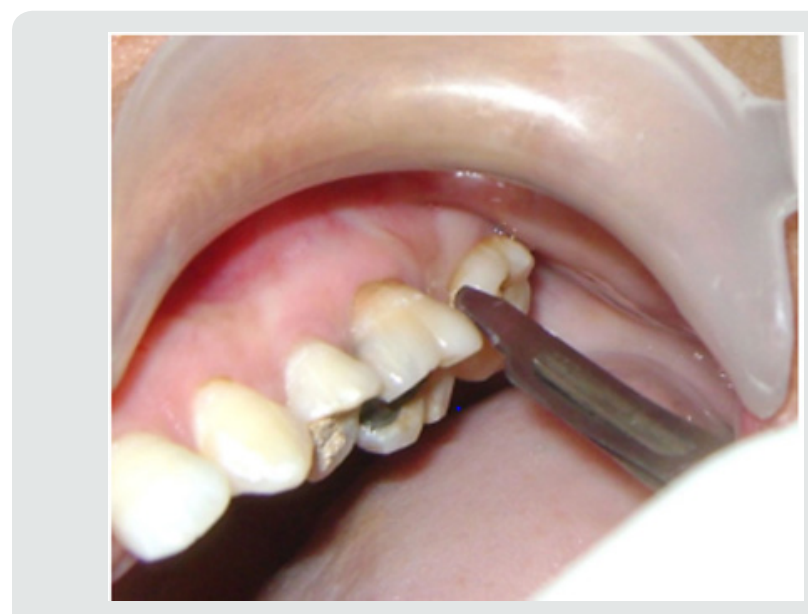

Figure 1: Incision at the surgical site.

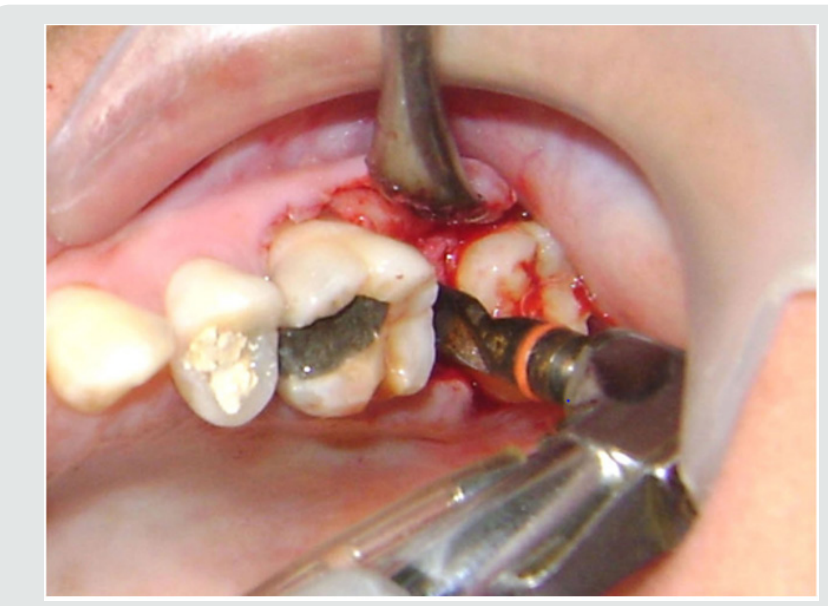

Figure 2: Osteotomy with twist drills.

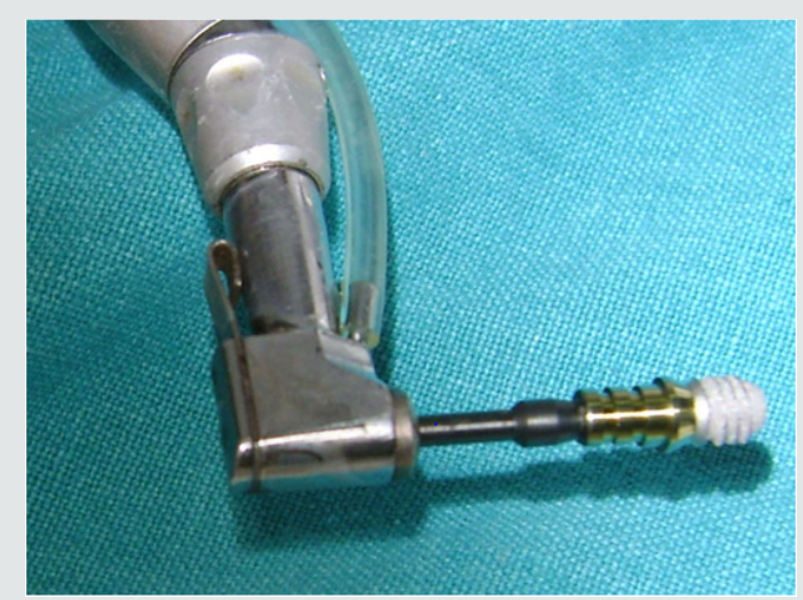

Figure 3: $5 \times 5 \mathrm{~mm}$ implant removed from sterile vial

The patient was recalled after a waiting period of 5 months for removal of the provisional prosthesis and making an elastomeric impression of the abutment screwed over the implant. In order to be efficient biomechanically, permanent suprastructure was provided with reduced occlusal table and flattened cuspal inclines. The PFM crown was fabricated in the laboratory and finally cemented in occlusion (Figures 5-7). After one year she was the called for a review. The intraoral radiographs were standardized using the long cone paralleling technique at $70 \mathrm{kvp}, 10$ ma specification and the exposure time as 0.8 seconds. The assessment was compared from the baseline i.e. the placement to one at 3-year post loading (Figure 8,9 ). No peri implant mesio- distal crestal bone loss was evident and the patient is further followed up.

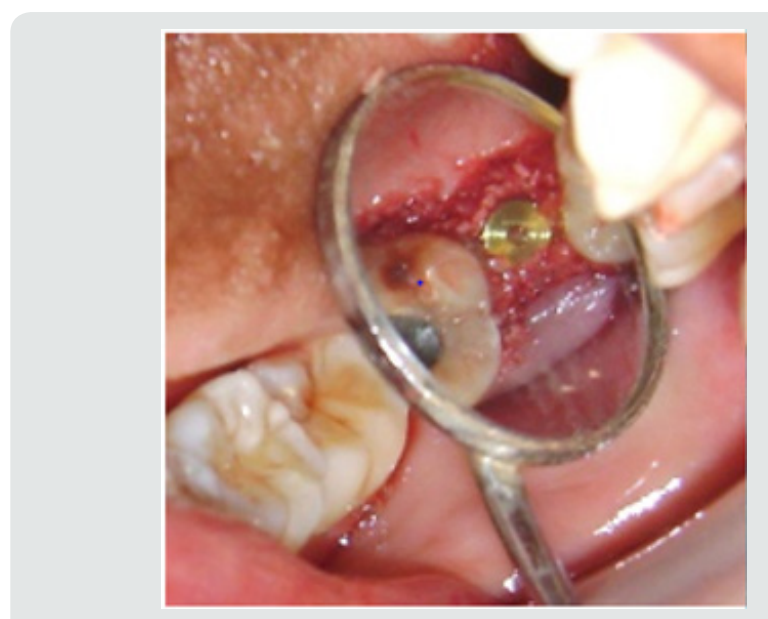

Figure 4: Cover screw tightened over fixture.



Figure 5: Abutment screwed over implant platform.

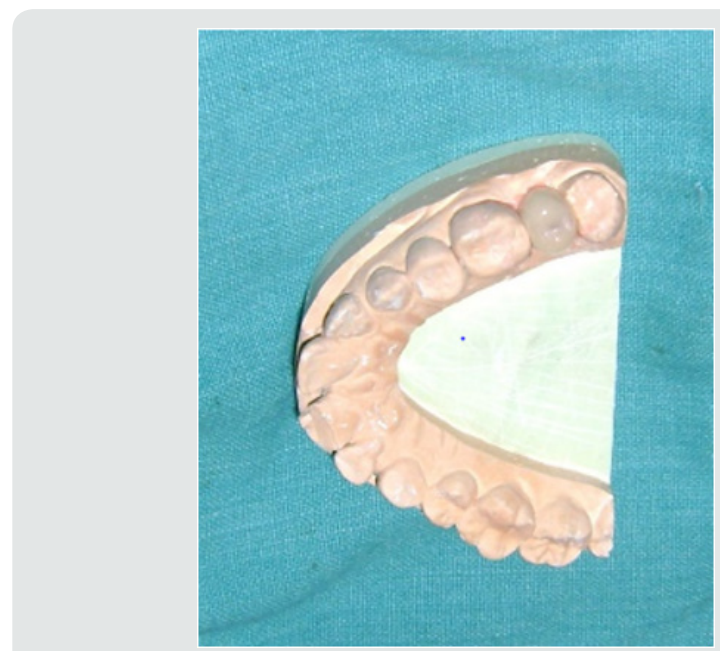

Figure 6: Crown fabricated on master cast. 


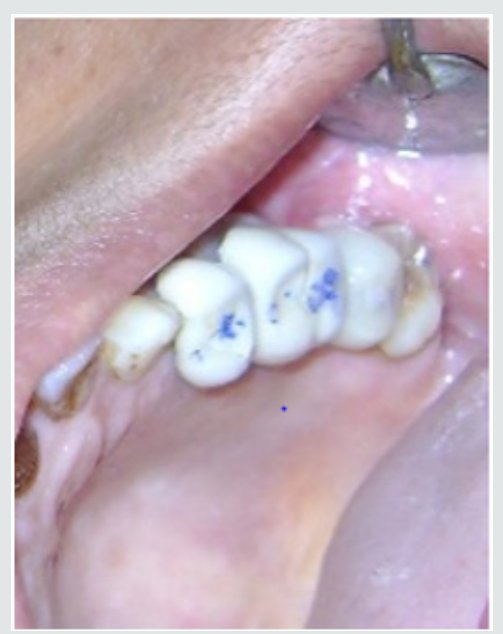

Figure 7: Prosthesis cemented in mouth.

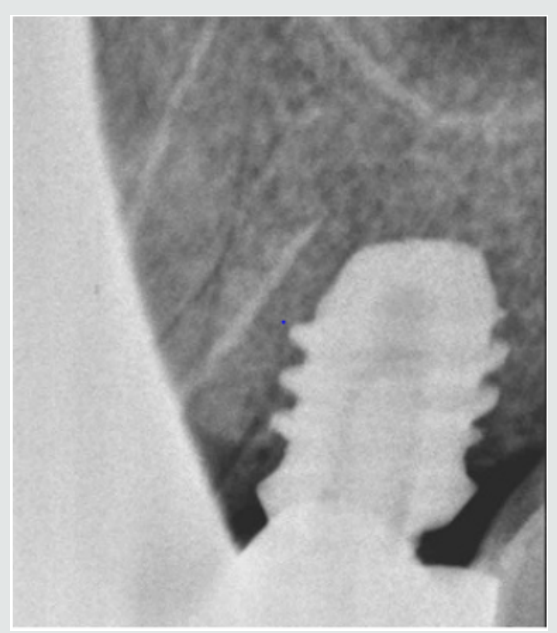

Figure 8: Baseline $\mathrm{X}$ ray

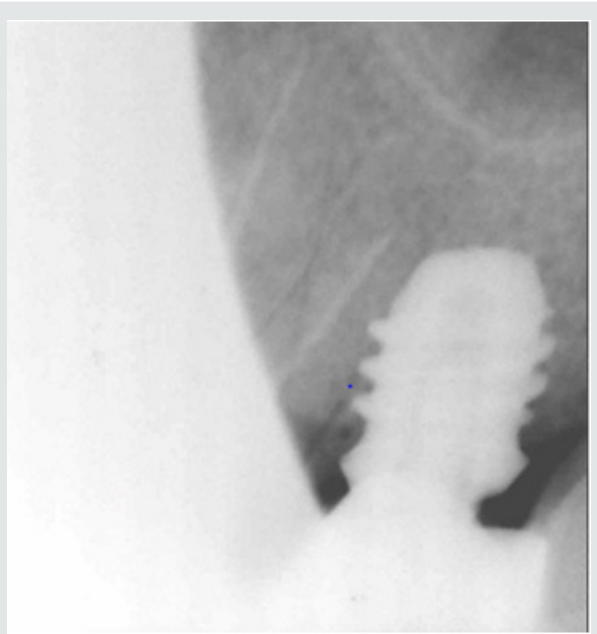

Figure 9: $X$ ray 3 years of loading

\section{Discussion}

The feasibility of long implants is most often questionable when mandibular nerve canal and maxillary sinus floor are in close proximity to the alveolar crest in lower and upper jaw respectively. Although vertical augmentation, along with nerve repositioning in the former and sinus elevation in the later case can restore an adequate bone height to place the implants of standard lengths, the associated risks of parasthesia, perforation and ultimately, the implant failure and patient morbidity cannot be ignored.

A paradigm shift is not very far from planning a skill- sensitive adjunct reconstruction towards performing a comparatively simple surgery with short implant. It is known that implant failures can be attributed to many factors but whereas many variables can be eliminated during surgery, bone quality is an exception [3]. Going by the location in oral cavity, posterior maxilla is poor quality and thus the size selection is more critical. An early fixture loss was observed with short cylindrical implant in the type IV bone found mostly in the above stated regions [6] The negative effects of parafunctional forces [6] and smoking [7] on the early loss of rigid fixation have been established. The above contraindications were ruled out in the present study for the same reason.

On the contrary, incorporation of surface roughness, selfthreading feature and greater width undoubtedly improves the predictability of a short implant. Despite only few studies, an observation was done on 19,083 dental implants [8] which concluded that rough-surfaced $7 \mathrm{~mm}$ implant was as successful as standard lengths. A wide fixture was introduced to replace the failing standard implant and for compromised bone with reduced height [9]. Similar to the present case, another successful attempt was shown previously using $5 \times 5 \mathrm{~mm}$ implant in a 56-year-old partially edentulous patient [10].

\section{Conclusion}

The acceptance of implant modality in private practice is ever increasing along with the denial for adjunct and risk- involving procedures. Clinical trials on short implants with improvised surface geometries and a careful prosthodontic planning have indeed gone in a right direction. Many more long-term ones need to follow with large sample sizes.

\section{References}

1. Quirynen M, Naert I, Van Steenberghe D (1992) Fixture design and overload influence marginal bone loss and fixture success in the Branemark system. Clin Oral Implants Res 3(3): 104-111.

2. Sennerby L, Roos J (1998) Surgical determinants of clinical success of osseointegrated oral implants: A review of the literature. Int J Prosthodont 11(5): 408-420.

3. Munjal S, Munjal S, Hazari P, Mahajan H, Munjal A, et al. (2015) Evaluation of specifically designed implants placed in the low-density jaw bones: A clinico-radiographical study. Contemp Clin Dent 6(1): 40-43.

4. Jemt T (1991) Failures and complications in 391 consecutively inserted fixed prosthesis supported by Branemark implants in edentulous jaws: A study of treatment from the time of prosthesis placement to the first annual checkup. Int J Oral Maxillofac Implants 6(3): 270-276.

5. Schincaglia GP, Thoma DS, Haas R, Tutak M, Garcia A, et al. (2015) Randomized controlled multicenter study comparing short dental implants $(6 \mathrm{~mm})$ versus longer dental implants $(11-15 \mathrm{~mm})$ in combination with sinus floor elevation procedures. Part 2: clinical and radiographic outcomes at 1 year of loading. J Clin Periodontol 42(11): 1042-1051. 
6. Jaffin RA, Berman CL (1991) The excessive loss of Branemark fixtures in the type IV bone: a 5- year analysis. J Periodontol 62(1): 2-4.

7. Bain CA, Moy PK (1993) The association between the failure of dental implants and cigarette smoking. Int J Oral Maxillofac Implants 8(6): 609615.

8. Pommer B, Frantal S, Willer J, Posch M, Watzek G, et al. (2011) Impact of dental implant length on early failure rates: a meta-analysis of observational studies. J Clin Periodontol 38(9): 856-863.
9. Langer B, Langer L, Hermann I, Erug M (1993) The wide implant: A solution for special bone situations and rescue for the compromised implant. Part I. Int J Oral Maxillofac Implants 8(4): 400-408.

10. Yi YS, Emanuel KM, Chuang SK. (2011) Short $(5.0 \times 5.0 \mathrm{~mm})$ Implant Placements and Restoration With Integrated Abutment Crowns. Implant Dent 20(2): 125-130.

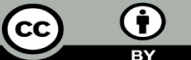

This work is licensed under Creative Commons Attribution 4.0 License

To Submit Your Article Click Here:

Submit Article

DOI: 10.32474/MADOHC.2019.03.000177

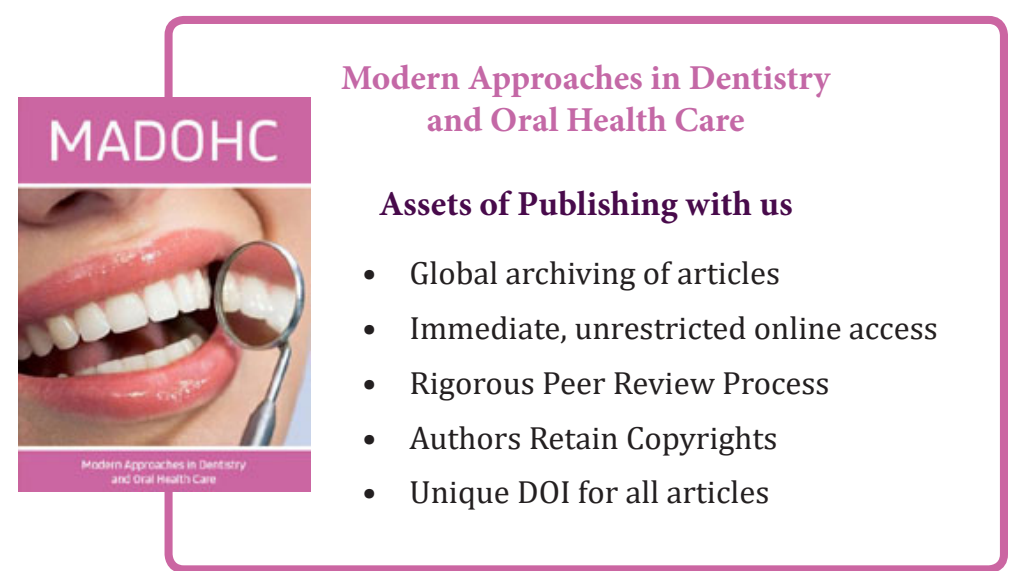

